\title{
Non-viable sperm in the ejaculate: Lethal escorts for Contemporary viable sperm
}

J. Roca, I. Parrilla, M. A. Gil, C. Cuello, E. A. Martinez and Heriberto Rodriguez-Martinez

\author{
Linköping University Post Print
}

Tweet

N.B.: When citing this work, cite the original article.

Original Publication:

J. Roca, I. Parrilla, M. A. Gil, C. Cuello, E. A. Martinez and Heriberto Rodriguez-Martinez, Non-viable sperm in the ejaculate: Lethal escorts for Contemporary viable sperm, 2016, Animal Reproduction Science, (169), , 24-31.

http://dx.doi.org/10.1016/j.anireprosci.2016.02.028

Copyright: Elsevier Masson

http://www.elsevier-masson.fr/

Postprint available at: Linköping University Electronic Press

http://urn.kb.se/resolve?urn=urn:nbn:se:liu:diva-129667

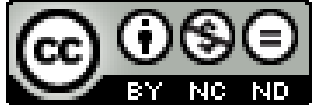


Non-viable sperm in the ejaculate: lethal escorts for contemporary viable sperm

\title{
J Roca1, I Parrilla1, MA Gilı, C Cuello1, EA Martinez1 and H Rodriguez-Martinez2
}

1Veterinary Medicine, University of Murcia, Murcia, Spain; 2Department of Clinical \& Experimental Medicine (IKE), University of Linköping, Linköping, Sweden.

Corresponding author: Jordi Roca (roca@um.es). Veterinary Teaching Hospital. Department of Medicine and Animal Surgery. University of Murcia. Campus de Espinardo. 30100 Murcia. Spain.

\begin{abstract}
Non-viable sperm (“dead sperm”) are present in variable numbers in mammalian ejaculates and their number increase substantially when semen is stored, particularly cryopreserved. This review comparatively highlights, with experimental data in porcine, the role-played by non-viable sperm in the outcome of semen used in assisted reproductive technologies. As well, the review discusses our current understanding of their origin and the pathways involved when their large numbers negative influence the functional lifespan of contemporary viable sperm to eventually cause irreversible dysfunction that reduces their fertility potential and their ability to develop healthy embryos. Finally, it highlights procedures currently available to mitigate these harmful effects.
\end{abstract}

Keywords: dead sperm, apoptosis, necrosis, oxidative stress, livestock species.

\section{Introduction}

The concept of non-viability in spermatology, irrespective of the species considered, is primarily related to the loss of integrity of the sperm plasma membrane, leading them to an irreversibly loss of homeostasis, immotility and death. Non-viable/dead sperm are part of any ejaculate, ranging 10 to $40 \%$, even from healthy individuals (boar: Sancho et al., 2004; bull: Murphy et al., 2013; stallion: Janett et al., 2003; buck: Barkawi et al., 2006; ram: Azawi and Ismaeel, 2012). In human more than 40\% of non-viable sperm are considered within WHO-physiologically limits in fertile men (Cooper et al., 2010). The presence of this offal-cell sub-population in the ejaculate reflects various disturbing phenomena during spermatogenesis, sperm maturation and interplay between sperm and seminal plasma (SP) during ejaculation. Moreover, in the ejaculate there is a weakened 
sperm population that will die during ejaculate handling (extension, storage, cooling or cryopreservation). This review aims to highlight the relevance of non-viable/dead sperm in both ejaculate and handled semen samples, assuming they play relevant negative effects on the functional lifespan of contemporary viable sperm.

\section{Where and how did ejaculated sperm become non-viable?}

The operating procedures leading to the presence of non-viable/dead sperm in the ejaculate are still unclear. Programmed cell death (apoptosis) is a main component of spermatogenesis, reaching to over $75 \%$ of the developing sperm (Huckins, 1978), to temper sperm over-proliferation by adjusting numbers of spermatogonia to those of Sertoli cells (Sakkas et al., 2003), which are ultimately responsible of removing the apoptotic cells by phagocytosis (Shaha, 2007). This functional removal is thought -but still debated (Cooper et al., 2002)- to continue in the epididymis, where a quality control mechanism identifies dead sperm (NagDas et al., 2000; D’Amours et al., 2012) that will

be subsequently removed by dissolution rather than phagocytosis (Jones, 2004). Since mammalian ejaculated sperm come from the sperm population stored in the cauda epididymis (Jones, 2004), it is plausible that a variable number of dead sperm stored and not yet removed together with others still viable but programmed to die are included among the cohort of sperm released in each ejaculation of healthy sires, as indicated by Correa-Perez et al. (2004) and Fernandez-Santos et al. (2011). A decline in androgen, ultimately responsible for epididymis function (Mann and Lutwak-Mann, 1981), in situations not specifically related to pathologies, as aging or following comfortless environmental conditions, for instance in reproductively seasonal species during the non-breeding season (Todini et al., 2007), leads to ejaculates with more nonviable sperm, which will further increase when the epididymal function is disturbed, either by biological agents or other causes, as heat stress (Durairajanayagam et al., 2015). Additionally, a cohort of weak albeit still viable epididymal sperm die along their transit through the deferent duct and the urethra (Ahmadi and Ng, 1999), damaged in their plasma membrane by either hydrostatic forces or their mixing with the secretion of the various accessory glands, which can cause transient changes in $\mathrm{pH}$ or osmolarity (Mann and Lutwak-Mann, 1981).

\section{Sperm also die after ejaculation, how?}

The number of non-viable/dead sperm tends to increase after ejaculation usually related 
to an inadequate post-ejaculation handling. Once ejaculated, spermatozoa are customarily extended in adequate buffered media, holding relevant substrates and cation-chelators, because SP has proven to be a bad medium to nurture the ejaculated sperm (Mann and Lutwak-Mann, 1981). The rationale behind is to bring adequate energy substrates for glycolysis and systems that could warrant sperm metabolism and keep cell homeostasis, with a focus on the most labile of all sperm structures: the plasma membrane. An unstable plasmalemma is synonymous with impending processes leading to disruption of its architecture, loss of motility and ultimately to the death. For further in vitro and/or in vivo use, extension is followed by storage, either in liquid or frozen state, to preserve sperm functionality and fertilizing capacity over time. However, large sperm numbers do not survive customary storage, which is attributable to sub-optimal storage methods, especially for cryopreservation, where cell losses can be as high as 30-50\% regardless of the species considered (Thurston et al., 2002). High extension rates together with dramatic changes in osmolality owing to solute accumulation and temperature effects experienced during freezing and thawing are considered the main harmful stresses adventuring the intactness of the sperm plasma membrane (Sieme et al., 2015).

\subsection{The earliest signs of deterioration}

One of the earliest modifications of a destabilized/deteriorating plasma membrane is the switching of the phospholipid phosphatidylserine (PS) from the inner to the outer face of the membrane (Peña et al., 2003; Aitken et al., 2015), a process related to capacitation and/or apoptosis (Aitken et al., 2015). Sperm capacitation, particularly in pigs, but also in other species, including human, is triggered by high levels of bicarbonate, which renders the plasma membrane more fluid and leads to the exteriorization of PS, particularly in the sperm head domain (Harrison and Gadella, 2005; Rodriguez-Martinez, 2007). This plasma membrane scrambling is directed by the membrane scramblase rather than by the deviating REDOX-mechanisms of apoptosis (de Vries et al., 2003). Moreover, it is since long known that externalization of PS may not be an early signal of apoptosis (Adayev et al., 1998) and that living cells, including sperm (Peña et al., 2003; deVries et al., 2003), can also express PS at their surface independent of cell death (van Genderen et al., 2008), related to membrane perturbation (Yang et al 2002), particularly during cooling (Peña et al., 2003).

3.2. What is behind the loss of viability of ejaculated sperm, apoptosis or necrosis?

To know how ejaculated sperm die is particularly relevant because the process leading 
to cell death determines the extent of the negative effects of dead sperm on contemporary viable sperm, especially once deposited in the female genital tract. The processes leading to the death of mature sperm remains debatable and controversies exist about whether it occurs through apoptosis, necrosis or across both pathways. Apoptosis and necrosis can occur independently, sequentially or simultaneously, at least in somatic cells (Elmore, 2007). Some authors consider that in species where the number of immature (holding substantial cytoplasmic rests) ejaculated sperm is high, as in human (Koppers et al., 2008) and bovine (Murphy et al., 2013), necrosis would be the dominant death process after ejaculation (Lachaud et al., 2004; Erickson et al., 2015). Matini Behzad et al. (2014) estimated that around 60\% of dead sperm in ram ejaculates die by apoptosis, while the remaining $40 \%$ dies by necrosis. Ejaculated sperm in human (Taylor et al., 2004), particularly among infertile individuals with large proportions of immature forms (Shukla et al., 2012), as well as of some domestic sires, stallion in particular, show apoptotic-like markers (PS, cysteine-proteases [caspases], etc.) (Bull: Erickson et al., 2015; ram: Martí et al., 2008; stallion: Gallardo-Bolaños et al. 2012; boar: Juarez et al., 2011). The markers can simply be remnants of the apoptosis during spermatogenesis (Shaha et al., 2010) showing which cells had escaped the process, but are still condemned to die post-ejaculation (Aitken and Baker, 2013; Aitken et al., 2015). In contrast to apoptosis, necrosis is an accidental cell death following severe cell stress, normally of external source, that either disrupt the functionality of the male genitalia or that directly harm sperm membranes integrity during or after ejaculation (Guthrie and Welch, 2005). Death by necrosis involves loss of homeostasis by the rupture of the cell membrane, the subsequent release of cytoplasmic enzymes and the breakdown of organelles, but without extensive nuclear damage (Bustamante-Marin et al., 2012). Sperm death by apoptosis will involve a primary sequentially increased production of Reactive Oxygen Species (ROS) by the mitochondria (redox generation), which induces a lipoperoxidation (LPO) cascade and the formation of lipid (electrophiles) adducts with proteins that can cause kinematic modifications and ultimately loss of motility by directly acting on flagellar proteins (Aitken et al., 2015). A further activation of present caspases might occur; whose increase anticipates further ROS attacks on the plasma membrane and the externalization of the PS. The PS is considered the main apoptosis-status marker for external phagocytes, leading to the concept of "silent death" because it does not cause cell lysis and therefore does not elicit an inflammatory/immune reaction/response during in vivo phagocytosis (Aitken and Baker, 2013; Aitken et al., 2015). Sperm 
necrosis, on the other hand, could trigger an immune response (Lu et al., 2013) as when sperm granulomas are built up.

\section{Impact of dead sperm on the functionality and fertilizing capacity of the contemporary viable sperm}

Non-viable/dead sperm coexist and interact with contemporary viable sperm in the semen samples produced from an ejaculate for storage and/or ART use, with the number of non-viable/dead sperm increasing in these processed semen over time. Remarkably this is not a simple function of time. The number of storage-related dead sperm is usually proportional to the number of dead sperm in the ejaculate (Brinsko et al., 2003; Martinez-Alborcia et al., 2012b). Consequently, presence of dead sperm in the ejaculate to be stored should be considered within the set of harmful stresses posed to the accompanying viable sperm population.

\subsection{Impact on the functionality of viable sperm}

The harmful effects of dead sperm on contemporary viable sperm during storage have been experimentally demonstrated in semen samples stored at liquid or frozen state. In liquid stored semen samples the harmful effect, recorded as a significant increase in the number of dead sperm, was revealed firstly by Shannon and Curson in 1972 in bull semen samples co-incubated with 33\% of additional dead sperm killed by repeated freezing and thawing cycles. A similar experiment was developed years later in stallion liquid stored semen samples (Brinsko et al., 2003), demonstrating that the presence of large proportions of dead sperm in the raw semen samples resulted in a significant increase in sperm death during storage and an impairment of the quality of the motility of viable sperm. However, the harmful effects of dead or non-viable sperm on contemporary viable sperm are particularly extensive in cryopreserved semen samples. Martinez-Alborcia et al. (2012b) demonstrated that the presence of large proportions of non-viable sperm in semen samples before and during freezing negatively influences the freezability of those viable, as evidenced by the reduced proportions of recovered viable and motile sperm post-thaw. Collectively, these results clearly demonstrated that a dead sperm population in raw semen samples is toxic for stored viable sperm. Additionally, Martinez-Alborcia (2012b) evaluated the functionality of cryosurviving sperm at 30 and 150 min post-thaw. Remarkably, presence of non-viable/dead sperm in the raw semen samples also altered the functionality of a large population of cryosurviving sperm, as evidenced by a sudden and sustained increase in the generation of ROS, particularly 
$\mathrm{H}_{2} \mathrm{O}_{2}$, alongside an increase in membrane fluidity with high rates of LPO. Moreover, the cryosurviving cells usually showed more fragmented nuclear DNA (Roca et al. 2013).

At this point, the question of how non-viable/dead sperm damage the viable contemporary cells is raised. Hydrogen peroxide $\left(\mathrm{H}_{2} \mathrm{O}_{2}\right)$ is very deleterious to spermatozoa, which is particularly evident in boars. Tosic and Walton (1946) first evidenced the ability of mammalian sperm to generate $\mathrm{H}_{2} \mathrm{O}_{2}$ and demonstrated later that boar sperm have poor capacity to eliminate $\mathrm{H}_{2} \mathrm{O}_{2}$ (Tosic and Walton, 1950). More recently, Awda et al., (2009) clarified that $\mathrm{H}_{2} \mathrm{O}_{2}$ is one of the most cytotoxic metabolites for viable boar sperm. Shannon and Curson (1972) demonstrated in bovine liquid stored semen that (i) dead sperm had high activity of $L$-amino acid oxidase (LAAO), the enzyme that catalyzes the generation of $\mathrm{H}_{2} \mathrm{O}_{2}$, and (ii) that its activity raised in the presence of egg yolk. These findings were extensive to liquid stored ovine sperm (Upreti et al., 1998) and more recently to cryopreserved equine sperm (Aitken et al., 2015), suggesting high LAAO activity, particularly in the sperm tail of dead sperm (Shannon and Curson, 1982), should be regarded as the ultimate responsible of the toxic effects of non-viable/dead sperm on contemporary viable sperm, at least in livestock species. LAAO activity is yet to be found in non-viable human sperm (Houston et al., 2015). Accordingly, the number of non-viable/dead sperm significantly contributes to raise the amount of $\mathrm{H}_{2} \mathrm{O}_{2}$ present in the semen samples, amounts that are higher in semen samples subjected to freezing in egg yolk based. Moreover, $\mathrm{H}_{2} \mathrm{O}_{2}$ in turn gives rise to other more aggressive free radicals, such as hydroxyl, via the classical Fenton and Haber-Weiss reaction. Consequently, $\mathrm{H}_{2} \mathrm{O}_{2}$ would be synthetized in mitochondria or, alternatively, in the cytoplasm of the sperm tail (Aitken and Koppers, 2011), to diffuse through the membranes of non-viable/dead sperm and thus being released to the extracellular medium, reaching contemporary viable sperm.

Again by association, the above observations would contribute to explain the reaction of viable sperm to the toxic effect of non-viable/dead sperm. The large amounts of ROS, particularly $\mathrm{H}_{2} \mathrm{O}_{2}$, released by dead sperm to the extracellular space would be responsible of the oxidative stress (OS) experienced by a variable number of contemporary viable sperm without these cells incurring in their own production of ROS becoming out of control. It is well known that dead and immature sperm together with leukocytes are the major sources of ROS in semen and they are more likely to generate high amounts of exogenous ROS leading to membrane changes in the contemporary viable sperm (Koppers et al., 2008; Murphy et al., 2013). The extent and 
relevance of OS in viable sperm would depend of (i) the amount of ROS released by dead sperm, that is demonstrated higher in cryopreserved than in liquid stored semen samples as indicated above, (ii) the period of exposition and the sensitivity of viable sperm to ROS, and (iii) the presence of ROS-scavengers. These assertions would be supported by the results reported by Brinsko et al. (2003), Ball (2008), MartinezAlborcia et al. (2012b) and Roca et al. (2013) when showing that while few dead sperm in raw semen samples do not induce an evident impairment in stored viable sperm, an increase in the number of dead sperm leads to substantial impairment. The above reports also showed that the OS was lesser in liquid stored than that in frozen-thawed viable sperm, as first OS-evidence requires $50 \%$ of dead sperm in liquid stored and just $25 \%$ in cryopreserved semen samples. Moreover, they also showed that the impairment in motility only affects the quality of kinematics in liquid stored samples, while it extends to the total of motile sperm in cryopreserved samples from raw semen samples with a similar large proportion of non-viable/dead sperm.

Sequentially, ROS released by dead sperm would lead to LPO in a variable number of viable sperm. Lipid peroxidation is the spontaneous result of OS and the sperm plasma membrane is particularly sensitive to peroxidative damage due to its high content in polyunsaturated fatty acids, the preferred target of free radicals (Mann and LutwakMann, 2011). A former report showed that an increase in the number of dead sperm is one of the contributing factors for increased levels of LPO (Upreti et al., 1998). Noteworthy, LPO occurs preferentially in viable sperm than in non-viable, as demonstrated using the fluorescent probe C11BODIPY581/591 (Silva and Gadella, 2006). Sperm LPO involves harmful changes in membrane fluidity and thereby leads to loss of sperm motility (Awda et al., 2009), probably by way of the toxic electrophilic lipid aldehydes generated by LPO, as 4-hydroxinonenal and/ 2-propenal -acrolein(Moazamian et al., 2015), that in turn induce a sudden and sustained increase of the mitochondrial ROS generation in viable sperm (Aitken and Baker, 2013), leading ultimately to death, showing many features reminiscent of apoptosis. Dead sperm in the raw semen samples also increase the percentage of spermatozoa showing fragmented nuclear DNA in stored semen samples (Roca et al., 2013). Although nuclear DNA damage in viable sperm as a result of direct OS induced by non-viable/dead sperm should not to be disregarded, such damage would be probably more related to the high and sustained ROS generation in mitochondria of own viable sperm (Aitken and De Iuliis, 2010). Consequently, the sequential death of viable affected sperm shows many 
of the stages present during a programmed cell death by apoptosis (Aitken and Koppers, 2011). However, it could be more as a result of attack from the escorting dead sperm than a true apoptosis. Cell death by necrosis can also involve increased ROS-generation in mitochondria as response to attack by aldehydes generated by LPO (Luo et al., 2005).

\subsection{Impact on the in vitro and in vivo fertilizing performance of viable sperm}

To the best of our knowledge, few studies have confirmed putative negative effects of non-viable/dead sperm on the in vitro and/or in vivo fertilizing performance of contemporary viable cells. To illustrate how dead sperm impairs in vitro embryo production capabilities of contemporary viable sperm, our research team carried out a few years ago an experimental study where boar semen samples with different proportions of dead sperm, killed by repeatedly freezing and thawing cycles, were cryopreserved and used -post-thaw- for in vitro fertilization (IVF) (Roca et al., 2013). The results showed that $50 \%$ or higher of dead sperm in raw semen samples before and during freezing negatively influenced the in vitro reproductive outcomes of cryosurviving cells, evidenced by a significant drop in fertilization rates combined with reduced embryo development. Most noticeably, the washing of thawed semen samples by gradient centrifugation did not reverse this scenario, despite significantly decreasing the percentage of dead sperm among the samples used for IVF, which would indicate that washing after thawing does not reverse the negative effects of dead sperm on contemporary viable sperm because the damage caused is already irreversible. Certainly, the impairment in the in vitro fertilizing capability of cryosurviving sperm was related to an increased ROS-generation and nuclear DNA-fragmentation among a large proportion of cryosurviving sperm. The impairment in in vitro embryo development would have been particularly related to the nuclear DNA damage. The study concluded that dead sperm in raw semen samples causes irreversible damage in a large population of frozen-thawed sperm rendering them unable for developing in vitro healthy embryos.

Relative to the effects on in vivo fertility, just one study, carried out by Baker and Degen in 1972, evaluated the negative putative effects of dead sperm on the fertilizing performance of contemporary viable sperm. Using an experimental approach, where gilts were inseminated either with only viable sperm or with a mixture (50\%/50\%) of viable and non-viable (killed in a microwave oven) sperm and later slaughtered to 
recover the genital tracts. The results showed that the number of sperm bound to the oocytes was 4-fold higher in the gilts inseminated with only viable cells, thus suggesting that the presence of non-viable sperm in the AI-dose also impairs the in vivo fertilizing capacity of viable sperm, at least in pigs. Collateral results achieved in a later study, whose aim was not focused to this topic, confirmed this theory when Alghamdi et al. (2004) inseminated mares two times during oestrus, the first AI using either (i) dead sperm, killed by snap-freezing in liquid nitrogen, or (ii) semen extender, while the second AI was done with viable sperm. Fertility was strongly reduced in the mares firstly inseminated with only dead sperm, which was attributable to an excessive uterine inflammation caused by the dead cells, as they may elicit a stronger inflammation than viable sperm. These results open for a new scenario, the response of the female genital tract to dead sperm present in the AI-dose, which should be regarded as another relevant negative effect of dead sperm, besides already known impairing of fertilizing capacity of viable sperm. Procedures for AI have evolved in domestic species and humans, including surpassing physiological barriers specific for the species considered, such as the cervical mucus in human or ruminants, where many sperm usually get caught (Morrell and Rodriguez-Martinez, 2011). This man-made modification implies that nonviable/ dead sperm are artificially placed in the uterine lumen, thus eliciting the abovedescribed reactions. Once semen AI-doses deposited in the uterus, phagocytes are capable to recognizing both viable and non-viable sperm facilitating their phagocytic removal (Woelders and Matthjis, 2001), which should be silent in the sense that it does not lead to a generation of pro-inflammatory cytokines and, consequently, an aggressive immune response against sperm, which seriously would compromise fertility, if longlasting. At this point, the pathway followed by the sperm to die, either by necrosis or apoptosis, is particularly relevant. Sperm dead by apoptosis exhibit PS on the outer face of the membranes that, once deposited into the female genital tract becomes the key signal for inducing a silent phagocytic process (Aitken and Baker, 2013), without any related inflammation in the surrounding tissue, facilitating in turn that viable sperm can successfully fertilize the oocytes. In contrast, dead sperm by necrosis promote the synthesis of pro-inflammatory cytokines by endometrium and, consequently, triggering an aggressive immune response against sperm that significantly reduces the chances of fertilization. In this context, it is interesting to note that an excessive ROS generation, as occurs in viable sperm exposed to large population of non-viable sperm, initiate inflammatory response and culminate in cytokine production (Holmström and Kinkel, 2014). It is relevant to remember that the above phenomena are present in AI-processed 
sperm doses, where the physiological presence of SP has been decreased, thus waiving some of its beneficial effects, particularly those related in modulating the immune response of female genital tract (Rodriguez-Martinez et al., 2011).

Summarizing, sperm dead by apoptosis, most probably from before ejaculation, and necrosis, as consequence of mishandling after ejaculation, coexist in semen samples and if they continued in the AI-doses will cause fertility impairment. The extent of impairment will depend on both the total number of dead sperm in the AI-doses and the proportion of them died by necrosis or apoptosis, leading to worse outcomes of fertility when the proportion of dead by necrosis is higher.

\section{How can the toxic effects of dead sperm be minimized?}

It is relevant to remember that the above phenomena are mainly present in processed semen samples, particularly in those cryopreserved, where the population of dead sperm is increasing and the physiological presence of ROS-scavengers is usually minimized. The latter relates mainly by the loss of relevance of SP, either by its dilution or even full elimination contemplated in many sperm preservation protocols (Rodriguez-Martinez et al., 2011). Consequently, the use of antioxidants, supplementing semen extenders and/or in the diet of animals, and removal of non-viable or dead sperm from raw semen samples as soon as possible after ejaculation, should be the two most effectives approaches that, used independently or together, would minimize the harmful effects of the non-viable/dead sperm on contemporary viable sperm.

\subsection{Antioxidant supplementation}

Knowing that the harmful effects of dead sperm on contemporary viable sperm are mediated by ROS, particularly $\mathrm{H}_{2} \mathrm{O}_{2}$, the first and most logical action would be inactivating them by using exogenous antioxidants. The supplementation of semen extender with either enzymatic or non-enzymatic antioxidants, such as catalase, glutathione peroxidase, quercetin, butylated hydoxytoluene or vitamin $\mathrm{E}$, has proven to be effective for scavenging excessive ROS generation and thereby preventing OS, resulting in turn a lowering intracellular $\mathrm{H}_{2} \mathrm{O}_{2}$ generation in viable sperm present in liquid storage semen samples (Agarwal et al., 2014). The same occurs in frozen-thawed semen samples when antioxidants are added in either freezing extender or thawing extender, or a combination of these (Bathgate, 2011).

Alternatively, antioxidants may also be supplied in the diet, a procedure more common in humans than in farm animals, being vitamin $C$, vitamin $E$ ( $\alpha$-T or other tocopherols) 
and glutathione the most commonly used oral antioxidants. Dietary supplementation with vitamin $\mathrm{C}$ and $\mathrm{E}$ and other antioxidants are effective in limiting membrane LPO and nuclear DNA damage, as demonstrated in livestock (Bathgate, 2011) and human (Gharagozloo and Aitken, 2011; Agarwal et al, 2014) sperm. However, their mechanism of action is still not well known. Liu et al. (2015) suggest that they modify the fatty acid composition of the sperm membranes making them more resilient to LPO. It is also necessary to consider that there may be potential negative effects when antioxidants are administered orally at high doses, as evidenced in human (Gharagozloo and Aitken, 2011).

Ideally, the treatment strategy using antioxidants should contemplate combining a dietary supplementation, preferably of vitamin E and selenium, which works synergistically with vitamin $\mathrm{E}$; together with supplementation of the semen extenders with antioxidant enzymes, such as glutathione peroxidase and catalase, able to neutralize excess of $\mathrm{H}_{2} \mathrm{O}_{2}$, the main ROS released from the dead sperm.

\subsection{Removing non-viable sperm from semen samples}

Removal of dead sperm from raw semen samples as quickly as possible after ejaculation would be the procedure of choice due to its straightforward design. Many techniques are currently available for selecting spermatozoa on the basis of relevant sperm characteristics, such as maturity, motility, morphology or viability, and some of them are a routine complement of in vitro ART procedures (Said and Land, 2011). It is worth considering that most of the techniques require time and skill, some are particularly expensive and not all of them work well with large volumes of semen, so only a few are suitable for being integrated into the routine procedures for elaborating insemination doses, either of liquid stored or cryopreserved semen, of farm animals.

Focusing on separating viable sperm of non-viable sperm, filtration techniques using either Sephadex columns or glass wool filters, could be chosen regardless of semen sample volume, as they are effective in removing dead or non-viable sperm allowing simultaneously a high recovery of viable sperm (Morrell and Rodriguez-Martinez, 2011). Another choice would be the use of techniques that are based on the centrifugation of semen samples through a colloid, allowing the separation of spermatozoa from seminal plasma and recovering most of motile and viable sperm of semen samples. Colloid centrifugation can be performed using several layers of colloid (Density Gradient Centrifugation, DGC), which is time consuming and therefore 
specifically used as a complement of in vitro ART procedures, or using just a single layer (Single Layer Centrifugation, SLC), easier to use and therefore useful and practical for implementing routine protocols for elaborating insemination doses of farm animals. Concerns have been raised that the sperm preparation media used for these density centrifugations could be deleterious for sperm, as once was the case for Percoll. Recently, a study by Aitken et al. (2014) clearly demonstrated that oxidative DNA damage is induced in human sperm prepared in PureSperm ${ }^{\circledR}$ discontinuous colloidal silicon gradients, owing to the contents in the media of metals known ( $\mathrm{Fe}, \mathrm{Cu}$ among others) to promote ROS-generation in the immediate vicinity of DNA. Although inclusion of chelators would probably ameliorate the outcome, this report is contradicted by another, more recent publication (Morrell et al 2016) where SLC of stallion semen was able to select sperm that produced less $\mathrm{H}_{2} \mathrm{O}_{2}$ than controls. Obviously, care should be taken when considering the method and particularly the formulation of the colloid used for preparing sperm. Single layer centrifugation of raw semen has also been proved effective for improving sperm cryosurvival, in terms of motility and viability, and for attenuating ROS generation in thawed viable sperm when applied to raw semen samples before freezing (Martinez-Alborcia et al., 2013). In addition to eliminating non-viable sperm, it would also be desirable to remove the viable sperm showing externalized PS, as they are already programmed to die, without matter if they do it via apoptosis, activation of scramblase or by exogenous ROS attack. These sperm can be separated after loading with Annexin-V-conjugated paramagnetic microbeads (which bind to externalized PS) using a magnetic-activated cell sorting system (MACS). The MACS is usually used in conjunction with DGC to exclude nonviable sperm. MACS is a high specific, simple, fast and inexpensive procedure but that requires special laboratory equipment (Said and Land, 2011), making it impractical as a complementary technique in routine elaboration of insemination doses. Annexin- $V$ coated glass wool filters could be a practical alternative to MACS for reducing the number of viable sperm showing apoptosis markers in semen samples (Grunewald et al., 2007).

Regardless of the sperm selection technique used it is, as already indicated above, important to remember that the removal of non-viable o dead sperm should be done as soon as possible after ejaculation or, in any case, always before semen liquid- or frozen storage. In addition to highlighting the harmful effects of dead sperm on viable sperm, Martinez-Alborcia et al. (2012a) and Roca et al. (2013) also demonstrated that removing dead sperm before freezing is much more effective than doing it after 
thawing, as evidenced in both functional lifespan and ability to generate in vitro healthy embryos of thawed viable sperm.

\section{Conclusions}

This review intends to alert of the negative impact of non-viable sperm in the functional lifespan of contemporary viable sperm. Clearly, there are a variable number of dead sperm in fresh ejaculates and thereby in raw semen samples that, when present in large numbers, become a silent killer for viable sperm. The harmful effects of dead sperm are a consequence of the extracellular release of free radicals, mainly hydrogen peroxide, that would cause irreversible dysfunctions in the plasma membrane of contemporary viable sperm, which would further display apoptosis-related markers as PS exteriorization and or even DNA-breaks that would eventually lead them to death. Of utmost importance is to consider that the effects of exogenous ROS built by the escorting non-viable cells would kill the viable sperm by causing LPO, damage of the plasma membrane and loss of motility, without these viable cells incurring in the customary establishment of apoptotic mechanisms themselves. The findings of apoptotic markers should be of a secondary nature. These harmful effects are especially evident during the storage of semen samples (time effect, elimination of endogenous antioxidants by extension or removal of threshold levels of SP) and particularly when they are frozen due to the exposure of sperm to the egg yolk (usual in the freezing extenders), which increase the LAAO activity in dead sperm and thereby the generation and extracellular release of $\mathrm{H}_{2} \mathrm{O}_{2}$. Affected contemporary viable sperm progressively loose their functional lifespan and in turn the ability to fertilize oocytes and to develop healthy embryos. Moreover, if the presence of large numbers of dead sperm continues in the AI-dose, they would trigger an aggressive inflammatory reaction in the endometrium against all sperm, which would seriously compromise in vivo fertility. If the number of dead sperm in semen samples is large, one should remove them as soon as possible after ejaculation or, optionally, always before storage. Antioxidant therapy, by adding antioxidants directly to the storage semen extender and/or as a supplement in the diet of the sires, should also be contemplated as an alternative or complementary measure.

\section{Acknowledgements}

The results cited by the authors were funded by the European Regional Development Fund and Spanish Government (MINECO-FEDER, AGL2012-39903 and MINECO 
AGL2015-69738-R); Seneca Foundation of Murcia (19892/GERM/15), The Swedish

Research Councils VR (Grant number 2011-6353), FORMAS (Grant number 2011-512) and FORSS (Grant nr 312971), Stockholm, Sweden.

\section{References}

Adayev, T., Estephan, R., Meserole, S., Mazza, B., Yurkow, E.J., Banerjee, P., 1998.

Externalization of phosphatidylserine may not be an early signal of apoptosis in neuronal cells, but only the phosphatidylserine-displaying apoptotic cells are phagocytosed by microglia. J. Neurochem. 71, 1854-1864.

Agarwal, A., Durairajanayagam, D., Du Plessis, S.S., 2014. Utility of antioxidants during assisted reproductive techniques: an evidence based review. Reprod. Biol. Endocrinol. 24, 12-112.

Ahmadi, A., Ng, S.C., 1999. Developmental capacity of damaged spermatozoa. Hum. Reprod. 14, 2279-2285.

Aitken, R.J., Finnie, J.M., Muscio, L., Whiting, S., Connaughton, H.S., Kuczera, L., Rothkirch, T.B., De Iuliis, G.N., 2014. Potential importance of transition metals in the induction of DNA damage by sperm preparation media. Human Reprod. 29, 2136-2147.

Aitken, J.B., Naumovski, N., Curry, B., Grupen, C.G., Gibb, Z., Aitken, R.J., 2015.

Characterization of an L-amino acid oxidase in equine spermatozoa. Biol. Reprod. 92, 125.

Aitken, R.J., Baker, M.A., 2013. Causes and consequences of apoptosis in spermatozoa; contributions to infertility and impacts on development. Int. J. Dev. Biol. 57, 265-272. Aitken, R.J., De Iuliis, G.N., 2010. On the possible origins of DNA damage in human spermatozoa. Mol. Hum. Reprod. 16, 3-13.

Aitken, R.J., Koppers, A.J., 2011. Apoptosis and DNA damage in human spermatozoa. Asian J. Androl. 13, 36-42.

Alghamdi, A.S., Foster, D.N., Troedsson, M.H., 2004. Equine seminal plasma reduces sperm binding to polymorphonuclear neutrophils (PMNs) and improves the fertility of fresh semen inseminated into inflamed uteri. Reproduction 127, 593-600.

Awda, B.J., Mackenzie-Bell, M., Buhr, M.M., 2009. Reactive oxygen species and boar sperm function. Biol. Reprod. 81, 553-561.

Azawi, O.I., Ismaeel, M.A., 2012. Effects of seasons on some semen parameters and bacterial contamination of Awassi ram semen. Reprod. Domest. Anim. 47, 403-406.

Baker, R.D., Degen, A.A., 1972. Transport of live and dead boar spermatozoa within the reproductive tract of gilts. J. Reprod. Fertil. 28, 369-377.

Ball, B.A., 2008. Oxidative stress, osmotic stress and apoptosis: impacts on sperm function and preservation in the horse. Anim. Reprod. Sci. 107, 257-267.

Barkawi, A.H., Elsayed, E.H., Ashour, G., Shehata, E., 2006. Seasonal changes in semen characteristics, hormonal profiles and testicular activity in Zaraibi goats. Small Rumin. Res. 66, 209-213. 
Bathgate, R., 2011. Antioxidant mechanisms and their benefit on post-thaw boar sperm quality. Reprod. Domest. Anim. 46, 23-25.

Brinsko, S.P., Blanchard, T.L., Rigby, S.L., Love, C.C., Varner, D.D., 2003. Effects of dead spermatozoa on motion characteristics and membrane integrity of live spermatozoa in fresh and cooled-stored equine semen. Theriogenology 59, 735-742.

Bustamante-Marín, X., Quiroga, C., Lavandero, S., Reyes, J.G., Moreno, R.D., 2012. Apoptosis, necrosis and autophagy are influenced by metabolic energy sources in cultured rat spermatocytes. Apoptosis 17, 539-550.

Cooper, T.G., Noonan, E., Von Eckardstein, S., Auger, J., Baker, H.W., Behre, H.M., Haugen, T.B., Kruger, T., Wang, C., Mbizvo, M.T., Vogelsong, K.M., 2010. World Health Organization reference values for human semen characteristics. Hum. Reprod. Update 16, 231-245.

Cooper, T.G., Yeung, C.-H., Jones, R., Orgebin-Crist, M.-C., Robaire, B., 2002. Rebuttal of a role for the epididymis in sperm quality control by phagocytosis of defective sperm. J. Cell Sci. 115, 5-7.

Correa-Pérez, J.R., Fernández-Pelegrina, R., Aslanis, P., Zavos, P.M., 2004. Clinical management of men producing ejaculates characterized by high levels of dead sperm and altered seminal plasma factors consistent with epididymal necrospermia. Fertil. Steril. 81, 1148-1150.

D'Amours, O., Frenette, G., Bordeleau, L.J., Allard, N., Leclerc, P., Blondin, P., Sullivan, R., 2012. Epididymosomes transfer epididymal sperm binding protein 1 (ELSPBP1) to dead spermatozoa during epididymal transit in bovine. Biol. Reprod. 87, 94.

De Vries, K.J., Wiedmer, T., Sims, P.J., Gadella, B.M., 2003. Caspase-independent exposure of aminophospholipids and tyrosine phosphorylation in bicarbonate responsive human sperm cells. Biol. Reprod. 68, 2122-2134.

Durairajanayagam, D., Agarwal, A., Ong, C., 2015. Causes, effects and molecular mechanisms of testicular heat stress. Reprod. Biomed. Online 30, 14-27.

Elmore, S., 2007. Apoptosis: A review of programmed cell death. Toxicol. Pathol. 35, 495-516.

Erickson, L., Kroetsch, T., Anzar, M., 2015. Relationship between sperm apoptosis and bull fertility: in vivo and in vitro studies. Reprod. Fertil. Dev. doi: 10.1071/RD14417.

Fernández-Santos, M.R., Soler, A.J., Ramón, M., Ros-Santaella, J.L., Maroto-Morales, A., GarcíaÁlvarez, O., Bisbal, A., Garde, J.J., Coloma, M.A., Santiago-Moreno, J., 2011. Effect of postmortem time on post-thaw characteristics of Spanish ibex (Capra pyrenaica) spermatozoa. Anim. Reprod. Sci. 129, 56-66.

Gallardo Bolaños, J.M., Miró Morán, Á., Balao da Silva, C.M., Morillo Rodríguez, A., Plaza Dávila, M., Aparicio, I.M., Tapia, J.A., Ortega Ferrusola, C., Peña, F.J., 2012. Autophagy and apoptosis have a role in the survival or death of stallion spermatozoa during conservation in refrigeration. PLoS One 7, e30688.

Gharagozloo, P., Aitken, R.J., 2011. The role of sperm oxidative stress in male infertility and the significance of oral antioxidant therapy. Hum. Reprod. 26, 1628-1640. 
Grunewald, S., Miska, W., Miska, G., Rasch, M., Reinhardt, M., Glander, H.J., Paasch, U., 2007. Molecular glass wool filtration as a new tool for sperm preparation. Hum. Reprod. 22, 14051412.

Guthrie, H.D., Welch, G.R., 2005. Effects of hypothermic liquid storage and cryopreservation on basal and induced plasma membrane phospholipid disorder and acrosome exocytosis in boar spermatozoa. Reprod. Fertil. Dev. 17, 467-477.

Harrison, R.A., Gadella, B.M., 2005. Bicarbonate-induced membrane processing in sperm capacitation. Theriogenology 63, 342-351.

Holmström, K.M., Finkel, T., 2014. Cellular mechanisms and physiological consequences of redox-dependent signalling. Nat. Rev. Mol. Cell Biol. 15, 411-421.

Houston, B., Curry, B., Aitken, R.J. 2015. Human spermatozoa possess an IL4I1 l-amino acid oxidase with a potential role in sperm function. Reproduction 149, 587-596.

Huckins, C., 1978. The morphology and kinematics of spermatogonial degeneration in normal adult rats: an analysis using a simplified classification of the germinal epithelium. Anat. Rec. 190, 905-926.

Janett, F., Thum, R., Niederer, K., Burger, D., Hässig, M., 2003. Seasonal changes in semen quality and freezability in the warmblood stallion. Theriogenology 60, 453-461.

Jones, R., 2004. Sperm survival versus degradation in the Mammalian epididymis: a hypothesis. Biol. Reprod. 71, 1405-1411.

Juarez, J.D., Parrilla, I., Vazquez, J.M., Martinez, E.A., Roca, J., 2011. Boar semen can tolerate rapid cooling rates prior to freezing. Reprod. Fertil. Dev. 23, 681-690.

Koppers, A.J., De Iuliis, G.N., Finnie, J.M., McLaughlin, E.A., Aitken, R.J., 2008. Significance of mitochondrial reactive oxygen species in the generation of oxidative stress in spermatozoa. J.

Clin. Endocrinol. Metab. 93, 3199-3207.

Lachaud, C., Tesarik, J., Cañadas, M.L., Mendoza, C., 2004. Apoptosis and necrosis in human ejaculated spermatozoa. Hum. Reprod. 19, 607-610.

Liu, J., Marey, M.A., Kowsar, E., Hambruch, N., Shimizu, T., Haneda, S., Matsui, M., Sasaki, M., Hayakama, H., Pfarrer, C., Miyamoto, A., 2014. An acute-phase protein is a regulator of sperm survival in the bovine oviduct: Alpha 1-acid-glycoprotein impairs neutrophil phagocytosis of sperm in vitro. J. Reprod. Dev. 60, 342-348.

Luo, J., Robinson, J.P., Shi, R., 2005. Acrolein-induced cell death in PC12 cells: role of mitochondria-mediated oxidative stress. Neurochem. Int. 47, 449-457.

Mann, T., Lutwak-Mann, C., 1981. Male reproductive function and semen. Springer-Verlag, Berlin Heidelberg.

Martí, E., Pérez-Pé, R., Colás, C., Muiño-Blanco, T., Cebrián-Pérez, J.A., 2008. Study of apoptosis-related markers in ram spermatozoa. Anim. Reprod. Sci. 106, 113-132.

Martinez-Alborcia, M.J., Morrell, J.M., Gil, M.A., Barranco, I., Maside, C., Alkmin, D.V., Parrilla, I., Martinez, E.A., Roca, J., 2013. Suitability and effectiveness of single layer 
centrifugation using Androcoll-P in the cryopreservation protocol for boar spermatozoa. Anim. Reprod. Sci. 140, 173-179.

Martinez-Alborcia, M.J., Morrell, J.M., Parrilla, I., Barranco, I., Vazquez, J.M., Martinez, E.A., Roca, J., 2012a. Improvement of boar sperm cryosurvival by using single-layer colloid centrifugation prior freezing. Theriogenology 78, 1117-1125.

Martinez-Alborcia, M.J., Valverde, A., Parrilla, I., Vazquez, J.M., Martinez, E.A., Roca, J., 2012b. Detrimental effects of non-functional spermatozoa on the freezability of functional spermatozoa from boar ejaculate. PLoS One 7, e36550.

Matini Behzad, A., Ebrahimi, B., Alizadeh, A.R., Esmaeili, V., Dalman, A., Rashki, L., Shahverdi, A.H., 2014. Improvement in vitro fertilization rate, decrease in reactive oxygen species and spermatozoa death incidence in rams by dietary fish oil. Reprod. Domest. Anim. 49, 599-605. Moazamian, R., Polhemus, A., Connaughton, H., Fraser, B., Whiting, S., Gharagozloo, P., Aitken, R.J., 2015. Oxidative stress and human spermatozoa: diagnostic and functional significance of aldehydes generated as a result of lipid peroxidation. Mol. Hum. Reprod. 21, 502-515.

Morrell, J.M., Rodriguez-Martinez, H., 2011. Practical applications of sperm selection techniques as a tool for improving reproductive efficiency. Vet. Med. Int. 894767. doi: 10.4061/2011/894767.

Morrell, J.M., Lagerqvist, A., Humblot, P., Johannisson, A., 2016. Effect of single layer centrifugation on reactive oxygen species and sperm mitochondrial membrane potential in cooled stallion sperm. Reprod Fertil Dev (in press).

Murphy, C., Fahey, A.G., Shafat, A., Fair, S., 2013. Reducing sperm concentration is critical to limiting the oxidative stress challenge in liquid bull semen. J. Dairy Sci. 96, 4447-4454.

NagDas, S.K., Winfrey, V.P., Olson, G.E., 2000. Identification of a hamster epididymal regionspecific secretory glycoprotein that binds nonviable spermatozoa. Biol. Reprod. 63, 1428-1436.

Peña, F.J., Johannisson, A., Wallgren, M., Rodriguez-Martinez, H., 2003. Assessment of fresh and frozen-thawed boar semen using an annexin- $\mathrm{V}$ assay: a new method of evaluating sperm membrane integrity. Theriogenology 60, 677-689.

Roca, J., Martinez-Alborcia, M.J., Gil, M.A., Parrilla, I., Martinez, E.A., 2013. Dead spermatozoa in raw semen samples impair in vitro fertilization outcomes of frozen-thawed spermatozoa.

Fertil. Steril. 100, 875-881.

Rodriguez-Martinez, H., 2007. Role of the oviduct in sperm capacitation. Theriogenology 68, 138146

Rodríguez-Martínez, H., Kvist, U., Ernerudh, J., Sanz, L., Calvete, J.J., 2011. Seminal plasma proteins: what role do they play? Am. J. Reprod. Immunol. 66 (Suppl 1), 11-22.

Said, T.M., Land, J.A., 2011. Effects of advanced selection methods on sperm quality and ART outcome: a systematic review. Hum. Reprod. Update 17, 719-733.

Sakkas, D., Seli, A., Bizzaro, D., Tarozzi, N., Manicardi, G.C., 2003. Abnormal spermatozoa in the ejaculate: abortive apoptosis and faulty nuclear remodelling during spermatogenesis. Reprod. 
Bio. Med. Online 7, 35-39.

Sancho, S., Pinart, E., Briz, M., Garcia-Gil, N., Badia, E., Bassols, J., Kádár, E., Pruneda, A., Bussalleu, E., Yeste, M., Coll, M.G., Bonet, S., 2004. Semen quality of postpubertal boars during increasing and decreasing natural photoperiods. Theriogenology 62, 1271-1282.

Shaha, C., 2007. Modulators of spermatogenic cell survival. Soc. Reprod. Fertil. Suppl. 63, 173186.

Shaha, C., Tripathi, R., Mishra, D.P., 2010. Male germ cell apoptosis: regulation and biology. Philos. Trans. R. Soc. Lond. B. Biol. Sci. 365, 1501-1515.

Shannon, P., Curson, B., 1972. Toxic effect and action of dead sperm on diluted bovine semen. J. Dairy Sci. 55, 614-620.

Shannon, P., Curson, B., 1982. Site of aromatic L-amino acid oxidase in dead bovine spermatozoa and determination of between-bull differences in the percentage of dead spermatozoa by oxidase activity. J. Reprod. Fertil. 64, 469-473.

Shukla, K.K., Mahdi, A.A., Rajender, S., 2012. Apoptosis, spermatogenesis and male infertility. Front. Biosci. 4, 746-754.

Sieme, H., Oldenhof, H., Wolkers, W.F., 2015. Sperm Membrane Behaviour during Cooling and Cryopreservation. Reprod. Domest. Anim. 50, 20-26.

Silva, P.F.N., Gadella, B.M., 2006. Detection of damage in mammalian sperm cells.

Theriogenology 65, 958-978.

Taylor, S.L., Weng, S.L., Fox, P., Duran, E.H., Morshedi, M.S., Oehninger, S., Beebe, S.J., 2004. Somatic cell apoptosis markers and pathways in human ejaculated sperm: potential utility as indicators of sperm quality. Mol. Hum. Reprod.10, 825-834.

Thurston, L.M., Watson, P.F., Holt, W.V., 2002. Semen cryopreservation: a genetic explanation for species and individual variation? Cryo Letters 23, 255-262.

Todini, L., Malfatti, A., Terzano, G.M., Borghese, A., Pizzillo, M., Debenedetti, A., 2007. Seasonality of plasma testosterone in males of four Mediterranean goat breeds and in three different climatic conditions. Theriogenology 67, 627-631.

Tosic, J., Walton, A., 1946. Formation of hydrogen peroxide by spermatozoa and its inhibitory effect of respiration. Nature 158, 485.

Tosic, J., Walton, A., 1950. Metabolism of spermatozoa. The formation and elimination of hydrogen peroxide by spermatozoa and effects on motility and survival. Biochem. J. 47, 199212.

Upreti, G.C., Jensen, K., Munday, R., Duganzich, D.M., Vishwanath, R., Smith, J.F., 1998. Studies on aromatic amino acid oxidase activity in ram spermatozoa: role of pyruvate as an antioxidant. Anim. Reprod. Sci. 51, 275-287.

Van Genderen, H.O., Kenis, H., Hofstra, L., Narula, J., Reutelingsperger, C.P.M., 2008. Biochim. Biophys. Acta 1783, 953-963.

Woelders, H., Matthjis, A., 2001. Phagocytosis of boar spermatozoa in vitro and in vivo. 
Reproduction 58S1, 113-127.

Yang, M.-Y., Chuang, H., Chen, R.-F., Yang, K.D., 2002. Reversible phosphatidylserine expression on blood granulocytes related to membrane perturbation but not DNA strand breaks. J. Leuk. Biol. 71, 231-237. 